\title{
European Union in the age of post-truth: Developing societal resilience before European Parliament elections 2019*
}

\author{
Y. Y. Kolotaev \\ St. Petersburg State University, \\ 7-9, Universitetskaya nab., St. Petersburg, 199034, Russian Federation
}

For citation: Kolotaev Y.Y. European Union in the age of post-truth: Developing societal resilience before European Parliament elections 2019. Vestnik of Saint Petersburg University. International Relations, 2020, vol. 13, issue 1, pp. 69-81. https://doi.org/10.21638/spbu06.2020.105

\begin{abstract}
The emergence of phenomena such as fake news, alternative facts, and new wave populism have resulted in a new pressing problem for most modern democracies in the Western world. They have stressed a conceptual shift within the social tendencies and processes, which has resulted in the creation of a post-truth world. The main characteristics of such phenomena can be described as the transition from an evidence-based, normative and factual discourse to an emotional, post-factual and populistic one. The reason for this can be found in the psychological and technical dimensions of contemporary society. A synthesis of postmodernist logic of falling metanarratives, with the spread of social media, altered the nature of the truth and the lie. In this context, the changes in European politics at the supranational level became particularly important. The threat of populism, which uses the post-truth discourse in its favour, has forced the EU to elaborate on a set of mechanisms to overcome the negative effects of fake news and disinformation. Meanwhile, the main idea of how to tackle the phenomena of the post-truth world is based on the principle of societal resilience. An adaptive environment towards stressful influence on the Union is nowadays the global aim of the EU and it became particularly important right before the 2019 European parliament elections. This research will provide an analysis of the preliminary and preparatory measures that had been undertaken by the EU and a more general overview of the EU's capacity to resist post-truth.
\end{abstract}

Keywords: post-truth, resilience, disinformation, fake news, European Union, European Parliament election.

\section{Introduction}

The public discourse in most European countries has experienced in recent years a major concern on the changing nature of the social and political environment. Starting with a new wave of the increasing influence of populist movements in nearly every EU country and their informational domination in the media it ended up in the manifestation of the creation of a post-truth environment. The year 2016 brought a series of influential examples, where political behaviour of different societies has tended to be "emotionally motivated" or "irrational" in the sense that it has rejected an evidence-based decision in favour of an affective one. The President Trump's Election and Brexit have served as an

* Some theses of this article were presented at the 13th Pan-European Conference On International Relations (11-14 September 2019, Sofia, Bulgaria) in the author's paper "The influence of the post-truth era on the European Union: European Parliament elections and societal resilience".

The research was supported by the grant of the Russian Science Foundation (project No 17-18-01110).

(C) Санкт-Петербургский государственный университет, 2020 
impetus for brought discussions on the shift from a factual political environment to a post-factual. In a more generalized sense, this means that reasoned decisions were denied, despite the possible consequences. The idea of a post-truth world was also promoted by the expert community because of the failure of most forecasts signalizing the lack of predictability in contemporary politics.

Nevertheless, it might be assumed that all the examples of lying and affective influence are nothing new to politics [1]. But it's not only about lying. Post-truth does not automatically mean rejection of truth and acceptance of lies, but "it refers to the blurring distinction between the two" [2, p.2] or, in other words, it leads to the "liberalisation of truth" [2, p. 24]. This liberalisation is partly driven by the deeply inherent "confirmation bias". Thus, emotions have ever served in favour of politicians. But the informatization of everyday life and the mediatization of the social sphere made the dissemination of different truths or lies even easier. Also, such concepts as "filter bubbles" or "echo chambers" signify the yet lacking knowledge about the influence of information technologies and modern media (in particular, in the hands of populists and radical political movements, but not only).

Despite the all-inclusive character of post-truth, most of the topic related researches are based on the two aforementioned examples. This reveals the necessity of a broader survey on the post-truth phenomena. Although there is a multitude of examples at the national level, this research gives an insight into the supranational or EU-level manifestations of the post-truth politics and how it is conceptualized in the EU strategies or the actions of EU institutions. In doing so, the theory of social resilience developed by such authors as P. Bourbeau [3] and D. Chandler [4] is applied to describe the EU's perception of some aspects of the post-truth environment (e.g. fake news, disinformation) and to categorize different kinds of countermeasures. Furthermore, the resilience theory gives a solid basis for an in-depth analysis of some mistakes in the EU's understanding of disinformation (fake news) as a predominantly external threat, ignoring the complex nature of today's information environment. This research focuses on the European Union because of the illustrative nature of the EU's disinformation campaign right before the $2019 \mathrm{Eu}$ ropean Parliament elections, which provides a yet understudied example of an attempt to counter some effects of post-truth.

\section{Post-truth. A contested concept?}

To introduce the concept of post-truth more definitively it is worth to take a look at the definition of this term proposed by Ignas Kalpolas in his "A Political Theory of PostTruth". He gives a broad interpretation of post-truth as "a general condition of detachment of truth-claims from verifiable facts and the primacy of criteria other than verifiability in the audiences' decision to affiliate themselves with a particular truth-claim, such claims being pitched to audiences as narrative fictions that constitute their own lived realities and explain the world" $[2$, p. 5]. This interpretation of this phenomena gives several important insights. First of all, by defining post-truth as a "condition" he marks it as a lasting environment, that is not attributed to a single political event. Secondly, he does not deny the existence of "truth-claims", but stresses their plurality and the personal wish of an individual to affiliate himself with a "truth". And finally, he points out its non-fact-based character, making any "truth-claim" a "narrative fiction" for a target audience. 
But what are the preconditions of such an environment? The academic and non-academic community provides a brought variety of such explanations, ranging from psychological and cultural to political and informational. They all have different degrees of persuasiveness. But all together they form the awareness of a shifting environment. Some authors even note, that the essential characteristic of post-truth "is the recognition, both within the study of these respective fields and within wider public discourse, that emotions matter" [5, p.419]. All the crucial factors that brought to such recognition are essentially connected to three main topics: media, algorithms (and big data), and distrust.

The "mediatization" of politics has revealed, that media change our current understanding of the social life [6;7]. They "have become co-constructive for the articulation of various social fields in their present form: politics, economics, education, and so on" [8, p. 321], thus making the social world nearly disappearing outside the media. The culture of "promotionalism" [9] drives politics to a show-like type of content. At the same time, alongside the general mediatization of everyday life, there is a process of decentralization happening. The appearance of social media gave an impetus to a rising number of information sources, thus contesting traditional media. This fragmentation of the media environment brought to an even more fragmented society with different groups consuming their "truths" through personalized information flow.

This personalized information flow is mostly enabled through algorithms and databased instruments and tools operating on social networks. They show the relevant content to a proper person, thus making him consume information, that corresponds to his sentiments. Furthermore, the "attention economy" [10], "culture of sensationalism and a focus on gaining clicks and views" [5, p. 421] fosters a distorted reality, where the content is displayed disproportionately [11]. In political circumstances, where personal data is collected and analyzed, it "can provide an extremely detailed picture of a person's life" [12, p.31], thus enabling a situation where "populations corresponding to beliefs and opinions are planned, produced, and managed by big data-driven predictive analytics and resourcerich strategic communication" [10, p.330].

Distrust became the third powerful engine of post-truth's spread. It has taken several forms. The most obvious one is populism. The popular discontent both with public media and governments or other political institutions became a strong motive to seek for an affective perspective on social problems. The fact that people in Western countries became attracted by marginalized or disenfranchised movements in the situation of a "declining numbers of voters in presidential and parliamentary elections across the West" [13, p. 20] demonstrates the spreading distrust. Different events, such as the 2008 financial crisis, the Iraq War are responsible for the loss of confidence in any influence on political processes [13, p. 21]. In European politics, another example of an event that has fostered a new wave of populism can be found in the 2015-2016 migration crisis. The mediatized environment accompanied by an acute social problem has utilized the public distrust to spread posttruth politics, as we currently know it. And so pluralism (that is so essential for a democratic state) has evolved into political polarization.

Despite all these evidence of post-truth interfering even deeper in the social reality, the post-truth concept itself is sometimes perceived as contested. This is due to the "current, largely non-academic wave of anxiety and interest" [14, p.1105]. Because of its initially non-academic manner, the term has been to a large extent politicized and used to express different meanings or even serve as a stigma in public debates. Nevertheless, 
in the academic discourse post-truth serves as an interdisciplinary or umbrella concept including a broad range of approaches, connected to psychology, media studies, political science, international studies, and even computer science.

But still, there are some assumptions about post-truth existing in the academic discourse, that tend to be rather doubtful. One of them brings post-truth in strict connection to postmodernism, as a cultural background [15]. "In fact, post-truth is not inspired by postmodernism but is, instead, a testament to the insightfulness of at least some of the postmodernist thinkers who have been able to predict something akin to the post-truth condition decades" [2], in other words, claiming, that postmodernism has caused post-truth is equal to "blaming a diagnosis for having caused the diagnosed condition" [2]. Thus, the "fall of metanarratives" is rather an implicit characteristic of the discussed conditions. The same goes for the supposedly relativistic nature of post-structuralism. "Post-structuralism is not a dogma that demands that we all reject 'facts'. The point is rather to recognise how particular ideas and practices gain the status of 'facts' or 'common sense' knowledge as a result of the way in which they are represented, abstracted or interpreted" [5].

The other rather questionable assumption on post-truth is the oversimplification of the concept by connecting it only to the problem of fake news, omitting the general context of distrust and political fragmentation. "Fake news", together with such notions as "alternative facts", "strategic misinterpretation", etc., reflect only particular aspects of the post-truth environment, or different instruments of post-truth politics. Therefore, while analyzing them, it is useful and necessary to keep in mind the cumulative effect of the aforementioned forces that drive democratic states across the globe (not only in Western states) into a jet unknown direction.

\section{Social resilience and post-truth. Some insights into the resilience theory}

The current limits of a broad post-truth theory have a multifaceted nature. Despite its politization, post-truth lacks a coherent understanding of whether it is a threat, that has to be counted, or just the current state of affairs in the social sphere. To accept post-truth as "normal" and natural for the modern world would be rather a mistake, with far-reaching consequences. But at the same time, the interpretation of post-truth as a thread leads to another common mistake, when it is perceived as an external danger that can be prevented trough restrictions, control and other types of limitations. Thus, fencing out and labelling others for being "post-truth" leads to a simplistic and even distorted understanding of the problem.

Thus, a creative reinterpretation of post-truth is needed. A way out can be found through the usage of the resilience theory. Resilience, yet another interdisciplinary concept, helps to structure the differences between the external and internal character of a threat or challenge. Resilience becomes in particular important as it dominates the discourse of European politics in different spheres, including the countering of disinformation.

Initially, resilience came from environmental science, where C.S. Holling opposed it to the notion of stability. He described resilience as "the ability of $\langle\ldots\rangle$ systems to absorb changes of state variables, driving variables, and parameters, and still persist" [16], whereby "resilience is the property of the system and persistence or probability of extinction is the result" [16, p. 17]. Another, a more social-oriented definition of resilience describes it as 
"the capacity of a system to absorb disturbances and reorganize while undergoing change so as still retain essentially the same functions, structure, identity, and feedback" [17]. Through its universal applicability resilience made its way into social sciences, psychology, economics, crisis management, and different other spheres. Starting from the 1970-s resilience has gradually evolved and presented several visions on the systematic reaction towards disturbances and disasters. These visions are well reflected in two classifications, one proposed by David Chandler and Jon Coaffee, and the other by Philippe Bourbeau.

The ladder consists of three types of resilience: as Maintenance, Marginality, and Renewal [3]. All of them are based on systemic logic. The first, resilience as Maintenance "is characterised by adaptation in which resources and energy will be expended in maintaining the status quo" [3, p.29]. Here the disturbances will be problematized by the dominant discourse, defining them as something "threatening and dangerous". Resilience as Marginality moves further by "bringing changes to the margins but do not challenge the basis of a policy" [3, p.29]. In this case, the discursive practices are producing marginal adjustments in the face of a problem, whereby the "problem" itself is in practice perceived as being less urgent. The third, resilience as Renewal "is characterized by responses that transform basic policy assumptions and, thus, potentially remodel social structure" [3, p.29]. This is the most transformative type of resilience, that brings in new types of policies and governance.

The other classification focuses on different relations between conservatism and interactivity. Chandler classifies resilience also in three categories articulating the homeostatic, autopoietic and ad hoc approaches [4]. Homeostasis in this sense means once again the maintaining of the status quo, or the "bouncing back" by "returning to the pre-existing equilibrium" and focusing on the internal properties of a society or system. The autopoietic approach is perceived as the second generation of resilience, which aims at growth and development through the process of "self-regulating". Thus, the most important characteristic becomes the "ongoing self-transformation $<\ldots>$ linked to "bouncing forward" [4, p.5]. The third approach is more subject-oriented by "developing resilience at the level of micro-politics or life-politics" [4, p.6]. Resilience in this context builds up engaged communities, where a problem is "reinterpreted as enabling and creating opportunities".

Altogether resilience is a concept that extends our understanding of any social dynamics in the face of disturbances. Of big importance is also the linkage between the external and internal characteristics of a crisis or challenge. There is no strict division between them as they are interconnected. The binary understanding does not help the problem solution. The awareness of consequences and side-effects leads to an approach, where "problems are not always seen as something external" but illustrate "our own lack of understanding or failure to be alert to changes..." [4, p.4].

\section{Resilience concept in the European political discourse}

The term "resilience" appeared in European politics in the 1980-s. As a concept itself, it has been integrated into a wider range of topics over the decades. Starting with environmental policy, it has later appeared in the context of economic relations. Since 1990-s the notion has been used in external relations with third countries [18]. In the second decade of our century, the concept started to appear regularly in different documents and regulations. In 2012 it appeared in the context of EU s development policy concerning the 
food crises in developing countries [18]. Thus, during a nearly four-decade-long evolution resilience has evolved in the European discourse spreading to topics related to the social, political and institutional dimensions.

It becomes even more obvious in the year 2016 when the European Union Global Strategy has been published. Here the term "resilience" has been used more than 40 times. In the Strategy, there is a strict connection between resilience and democracy noting, that a "resilient society featuring democracy, trust in institutions, and sustainable development lies at the heart of a resilient state" [19]. Still, there are contradictions in its usage, since the Global Strategy, using the word "resilience", does not apply its theoretical assumptions. First of all, it securitizes a range of threats, with the focus on the threats themselves, and not on the internal resources of the system [18, p.22]. Hybrid threats and disinformation are among those threats, placed in the context of external actions and the creation of strategic communications, that should be carried out by the EU to "offer rapid, factual rebuttals of disinformation".

This concept of resilience towards disinformation can be also found in the EU's 2017 Joint communication "A Strategic Approach to Resilience in the EU's external action". In this document, resilience is also presented as the aim of strategic communications mentioning, that "measures to increase citizens' resilience to hostile disinformation will be further developed by raising awareness, by supporting greater media plurality and professionalism, and by communicating positive narratives and fact-based messages" [20]. Altogether this understanding of disinformation has predetermined the anti-disinformation strategy of the EU in the run-up to the 2019 elections, forming the framework for further actions.

\section{Disinformation and post-truth: External or internal threat?}

The outlined willingness to counter disinformation during and beyond the European elections was the result of the aforementioned trend towards post-truth politics. The examples all around Europe brought to the necessity to withstand and fight against an aggressive emotional environment. In the year 2016 the President of the European Council, Donald Tusk, twittered, that "post-factual reality and post-truth politics pose a great challenge on both sides of the Atlantic" [21]. The flood of such categories as fake news, strategic communications, disinformation, propaganda, and misinformation into politics and media speech opened up the public debate to what can be perceived as a threat and how to counter it. In some countries the government undertook actions to block the promoters of misinforming type of content (Lithuania), others developed internal regulations (Germany, France), whereby often all the post-truth related words became mixed up, without being properly used or categorized.

The major contradiction that appeared, as a result, is the question, whether all the false information, disseminated per social media, has an exogenous or endogenous nature (Table 1). The relevant points of view to this question speculate on the possible sources of fake news. From one perspective, the main reason for the proliferation of misinformative and emotions-appealing content is the internal threat of populism. The populistic discourse fosters the creation of affective statements or content, thus enabling the populistic political groups to gain bigger influence. Jean-Claude Juncker, the President of the European Commission, expressed before the European elections the fear of internal fake news 
proliferation. In April 2019 he claimed: "I can see an attempt to rig the European Parliament elections. This comes from several quarters, and not only from outside the EU. States within the EU are also seeking to direct the will of voters in a particular direction with fake news" [22]. A similar message was delivered by Ramón Luis Valcárcel Siso, the European Parliament's ex-Vice president, who stressed the necessity to ensure, that "anti-democrats don't win at the ballot boxes" because of the "division sowed by populists and nationalists, through a discourse of hatred, lies and half-truths and proven falsehoods" [23].

The other perspective is the opposite one, focusing on the external characteristic of false information (disinformation). This point of view was conceptualized in the European Parliament resolution of 23 November 2016 on "EU strategic communication to counteract propaganda against it by third parties". Here the main source of fake news is perceived to be Russia, thus, externalizing the threat of fake news and disinformation. In a statement on the Action plan to counter disinformation Andrus Ansip, the ex-Vice-President of the European Commission and the ex-European Commissioner for the Digital Single Market, highlighted, that "there is strong evidence pointing to Russia as a primary source of disinformation in Europe" [24], considering that "disinformation is part of Russias military doctrine and its strategy to divide and weaken the West" [24]. The same attitude can be noted in the statements of Federica Mogherini, High Representative of the European Union for Foreign Affairs and Security Policy. At the press conference following the Foreign Affairs Council in 2018, she stressed "a challenging Russian behaviour in many different fields" [25], highlighting that the "areas of challenging Russian behaviour include $\langle\ldots\rangle$ activities of disinformation, internal interference, hybrid threats, malicious cyber activities..." [25].

Table 1. Positions on the nature of false information in the European discourse (made by the author)

\begin{tabular}{|l|l|}
\hline \multicolumn{1}{|c|}{ Endogenous threat } & \multicolumn{1}{|c|}{ Exogenous threat } \\
\hline $\begin{array}{l}\text { "I can see an attempt to rig the European Parliament } \\
\text { elections. This comes from several quarters, and not } \\
\text { only from outside the EU.States within the EU are } \\
\text { also seeking to direct the will of voters in a particular } \\
\text { direction with fake news" (Jean-Claude Juncker) }\end{array}$ & $\begin{array}{l}\text { "Distrong evidence pointing to Russia as } \\
\text { "Drimary source of disinformation in Europe", } \\
\text { and its strategy to divide and weaken the West" } \\
\text { (Andrus Ansip) }\end{array}$ \\
\hline $\begin{array}{l}\text { "Anti-democrats don't win at the ballot boxes", "A challenging Russian behaviour in many different } \\
\text { "Division sowed by populists and nationalists, } \\
\text { through a discourse of hatred, lies and half-truths } \\
\text { and proven falsehoods" (Ramón Luis Valcárcel Siso) }\end{array}$ & $\begin{array}{l}\text { ields", "Areas of challenging Russian behaviour } \\
\text { include... activities of disinformation, internal } \\
\text { interference, hybrid threats, malicious cyber } \\
\text { activities..." (Federica Mogherini) }\end{array}$ \\
\hline
\end{tabular}

Altogether this duality in regard to the threat of fake news is currently leaned towards the second approach. This will be described further on and can be very well traced in the Action Plan against Disinformation [26]. Despite the social consensus about the possible danger of fake news produced by different radical political groups inside the EU, the main attention is dragged towards the external aspect of a post-truth environment. In this regard, the term post-truth itself becomes meanwhile part of the academic apparatus thereby disappearing from political discourse. But this disproportion in the perception of the external and internal aspect of the post-truth phenomena brings in a distorted understanding of how to develop social resilience towards it. 
The contemporary information environment, that can be characterized as open, in states with a liberal and open democratic regime does not allow to separate the external and internal character of the content inside the internet, and the social networks. Thereby, the main distributor of content often provides the advertising mechanisms and algorithms to all interested and involved parties. The decentralized nature of information proliferation, in contrast to the traditional media, involves the originally exogenous content into a common system, thus making a potential danger into a part the internal environment, not allowing the system to isolate itself. In terms of resilience theory, this means a shift from "defense" against external danger, towards "resilience" as a category of self-adaptation to it [27]. Despite its commitment towards the category of resilience, the EU has failed so far to identify the twofold nature of post-truth influencing the European society. The distinction between fake news from populists and disinformation from without during the counteraction is ineffective, because, by only focusing on one aspect of the emotional information sphere, the omission of the second leads to an incomplete adaptation or solution of a problem. This distinction between the external and internal can be even better understood through the analysis of gradual change in the key categories of post-truth prevention in the EU.

\section{Strategic communication, fake news, disinformation}

Even with the acceptance of fake news as a threat to European society, there is still a difficulty to understand what this type of false information is. In the academic discourse, there is a broad variety of interpretations ranging from a multifaceted nature of fake news [28], to the complete denial of the appropriates of such a category in general [29]. Fake news can thus include a big variety of phenomena, including disinformation, different types of misinformation, parody and falsehoods [28].

The European Union itself gradually developed its understanding of the nature of fake news. At the very start of the Ukrainian crisis the major category used by EU officials was propaganda or strategic communications. The European Parliament resolution "On EU strategic communication to counteract propaganda against it by third parties" once again constitutionalized this development [30]. Further on, in the year 2016, after the promotion and popularisation of the words post-truth the central category became the identification of false information in form of fake news, which has the aim to destabilize electoral campaigns. This has coincided with the early steps of "fake news prevention" in the EU [31]. But early in the year 2018, another shift in the vocabulary of the EU documents has happened. The notion "fake news" becomes replaced by "disinformation". The reason was a Report of the High-Level Expert Group on fake news and disinformation [29]. In general, there were two reasons why the EU has moved away from the term "fake news". First of all, it has been blamed to be very politicized. The second reason was that it is very conditional and unclear by nature. Thus, disinformation becomes the main concept and term in every new document and strategy on the countering of the threat of false information.

As a result, three different terms appear in the public discourse and official documents of the EU. The shift towards the notion of disinformation illustrates once again the externalization of the threat. A strong connection to the information warfare and Russia separates the current actions from the internal aspect. At the same time "disinformation" as a word, that has been used throughout the Cold war does not reflect the specificity of 
the issue the EU is facing. As a result, such mechanisms as targeting, information foods, and filter bubbles are not implicit to the notion of disinformation.

Still, this pluralism of terms can be seen during the whole pre-election period in the EU. The whole debate on free and fair elections was dominated by the understanding of a necessity to counter the misinformative impact on the elections. And to illustrate the different approaches towards fake news prevention once again resilience theory should be applied. Despite some difficulties in the application of resilience theory to post-truth in the case of EU, it still can give us a better understanding of the different strategies to counter disinformation.

\section{European Parliament elections and post-truth/disinformation prevention}

Through the lens of resilience, disinformation can be interpreted as a system-disturbing factor. Its impact on the curtail aspects of information infrastructure drives us to its inclusion into the system as a disturbance, that needs an adaptation mechanism inside the system. Overall, in the EU practice, two ways to project and create this adaptation can be found. Both were developed during the period 2015-2018. On its final stage (2018-2019) the focus was to prepare the European society to the influence of disinformation during the 2019 Elections. One of the elaborated approaches can be referred to as "paternalistic", including different forms of protective interventions into the public sphere to prevent the dissemination of false information. The other approach can be described as "adaptive" and refers to a liberal kind of thinking, stressing the importance of freedom of speech and is closely related to adaptivity itself.

Originally, the first approach, that emerged in the EU was the paternalistic one. It tended to introduce the bouncing back (homeostatic approach towards resilience) to the previous condition of the system, thereby focusing on the internal resources of the society, externalizing the threat [4]. The main forms of counteracting are restrictions, normative regulations, institutional involvement $[32 ; 33]$ and even the imposition of counterpropaganda [34].

Initially, this approach could be associated with the actions of the European Parliament and the European External Action Service. The establishment of the East StratCom Task Force, an institution of strategic counter-narrative proliferation, in 2015 can be seen as the first initiative in this direction. Than the EP Resolution of 2016 followed up, underlining "the crucial need to ensure resilience of the information systems at EU and Member State level" [30] and calling the European Commission "to advance certain legal initiatives in order to be more effective and accountable in dealing with disinformation and propaganda and to use the midterm review of the European Neighbourhood Instrument to promote the strengthening of the resilience of the media as a strategic priority" [30]. The appeal to legal initiatives reveals once again the paternalistic nature of this kind of threat prevention. A further step in this direction can be found in the European Parliament resolution of 15 June 2017 on online platforms and the digital single market, where the EP "Calls on the Commission to analyze in-depth the current situation and legal framework with regard to fake news, and to verify the possibility of legislative intervention to limit the dissemination and spreading of fake content" [35]. All these examples tend to recreate the conditions before the impact by limiting the danger. 
An alternative adaptive approach emerged consequently throughout the evolution of disinformation prevention. It is closely related to the autopoietic or self-regulating approach, to bounce forward through the evolution of the social system on the next stage of resilience to the danger [4]. Thus, this approach focuses not on the responding to the danger, but on the development of mechanisms to contain the influence through the adaptation to a threat, therefore bringing the society on a qualitatively new level of coexistence with the threat. This way of thinking has been promoted by the European Commission since the beginning of 2018 .

The key documents elaborated by the Commission are the Action Plan against Disinformation (JOIN(2018) 36 final), Communication - Tackling online disinformation: a European Approach (COM/2018/236 final) and the Final Report of the High-Level Expert Group on Fake News and Online Disinformation. The Final report of the HLEG was the result of public consolations and it proposed a multidimensional approach towards disinformation. This multidimensionality included the increasing openness of media, fostering of media-literacy, the widening of users' involvement in the process of fake news prevention, and further researches [30]. An important point is that the measures proposed in this report aim "instead to provide short-term responses to the most pressing problems, longer-term responses to increase societal resilience to disinformation, and a framework for ensuring that the effectiveness of these responses is continuously evaluated, while new evidence-based responses are developed" [29]. This idea was carried out further on in the "Tackling online disinformation" Communication, which manly overlap with such principles promoted by the HLEG report as openness, development, trust, and inclusiveness. For the first time, the Communication puts forward the aim to promote a "secure and resilient election processes" with a direct connection to the 2019 European Parliament elections [36]. The adaptive logic of the Communication brought also to the creation of a Code of Practice on Disinformation, which is a self-regulatory standard to fight disinformation agreed by representatives of online platforms, leading social networks, advertisers and advertising industry [37].

The latest adapted document on disinformation is the Action Plan against Disinformation, which represents the current strategy of the Commission. It represents the essence of the adaptive logic, by including all the gathered experience. "The coordinated response to disinformation presented in this Action Plan is based on four pillars: (i) improving the capabilities of Union institutions to detect, analyse and expose disinformation; (ii) strengthening coordinated and joint responses to disinformation; (iii) mobilising private sector to tackle disinformation; (iv) raising awareness and improving societal resilience" [26]. The Action plan was also set up as an instrument to secure the European Parliament elections from being influenced by disinformation. All of the four pillars stressed the need not to constrain the dissemination of disinformation, but to expose it, making the society resilient to the threat itself. Awareness, thus, is the key to an adaptive environment.

Both aforementioned strategies (Table 2) represent the current state of affairs in the EU's understanding of post-truth prevention. Despite its focus on its external characteristics (e. g. disinformation), the shift to an adaptive logic provides a more resilient way of dealing with its consequences by strengthening the societies ability to cope with the threat. But still, the externalization and securitization of disinformation as an exogenous threat brings in a distorted view on the post-truth environment.

However, a brief overview of the results of the 2019 elections shows that the strategy chosen by the EU gave a moderate result. Following the Report on the implementation of 
Table 2. EU's approaches to counter disinformation (post-truth) (made by the author)

\begin{tabular}{|l|l|}
\hline \multicolumn{1}{|c|}{$\begin{array}{c}\text { Paternalistic (homeostatic) approach } \\
\text { bouncing back }\end{array}$} & \multicolumn{1}{|c|}{$\begin{array}{c}\text { Adaptive (autopoietic) approach } \\
\text { bounce forward }\end{array}$} \\
\hline $\begin{array}{l}\text { Main forms of counteracting disinformation: re- } \\
\text { strictions, normative regulations, institutional } \\
\text { involvement, imposition of counterpropaganda } \\
\text { (counternarrative) }\end{array}$ & $\begin{array}{l}\text { Main forms of counteracting disinformation: } \\
\text { openness of media, fostering of media-literacy, the } \\
\text { widening of users' involvement into the process of } \\
\text { fake news prevention, further researches, self-regu- } \\
\text { latory standards (mobilizing private sector), raising } \\
\text { awareness }\end{array}$ \\
\hline $\begin{array}{l}\text { European External Action Service, } \\
\text { European Parliament (2016-2017) }\end{array}$ & $\begin{array}{l}\text { European Commission, } \\
\text { European Parliament (2018 - now) }\end{array}$ \\
\hline $\begin{array}{l}\text { East StratCom Task Force; } \\
\text { European Parliament resolution of 23 Novem- } \\
\text { ber 2016 on EU strategic communication to } \\
\text { counteract propaganda against it by third parties } \\
\text { (2016/2030(INI)); } \begin{array}{l}\text { European Parliament resolution of 15 June 2017 on } \\
\text { online platforms and the digital single market/ }\end{array}\end{array}$ & $\begin{array}{l}\text { Action Plan against Disinformation (JOIN(2018) } \\
\text { Communication - Tackling online disinformation: } \\
\text { a European Approach (COM/2018/236 final); } \\
\text { Final report of the High Level Expert Group on Fake } \\
\text { News and Online Disinformation; } \\
\text { Code of Practice; } \\
\text { European Parliament resolution of 3 May 2018 on } \\
\text { media pluralism and media freedom in the } \\
\text { European Union (2017/2209(INI))/ }\end{array}$ \\
\hline
\end{tabular}

the Action Plan Against Disinformation, there were no major attempts of disinformation detected, and the populist parties haven't gained a spectacular result [38]. What is nevertheless important is that the rise of public averseness has led to one of the best participation rates for several decades. But yet the threat of disinformation and fake news is still there, and the EU will surely preserve its course on developing social resilience to it.

\section{Conclusion}

This research aimed to provide an insight into the European understanding of the post-truth phenomena and the different approaches of how to handle it. Thus, it has focused on the pre-election period and does not give a detailed analysis of the results themselves. The examination of the practical and discursive aspect of the EU's actions and perception towards disinformation showed that there is a difference in the understanding of how post-truth influences the EU. The duality of perception, what the nature of false information (disinformation) can be, is present in the EU discourse. But the dominant point of view, that the disinformation has an external source, has predetermined the actions undertaken by the EU before the Parliament elections.

The need to establish a resilient environment towards disinformation led to the establishment of two major strategies: the adaptive and paternalistic approach. But the externalization of the problem has created a major difficulty in the development of social resilience towards post-truth. The exclusion of the fake news and disinformation produced by internal actors in the discourse leads to a distorted picture of the post-truth environment and the current state of affairs in general. At the same time, in practice, the externalization has low influence in the adaptive approach, because it does not separate 
the threat from the society itself, thereby focusing on further transformations and the capabilities of a society. But, if the paternalistic approach is still applied (and there is a lot of cases of paternalism in national politics) to counter disinformation, it focuses only on one source from many, simplifying the threat itself, or even creating a counter-narrative, that tends to become itself an irrational distortion of reality.

\section{References}

1. Finlayson, L. (2019), What to Do with Post-Truth, Nordic Wittgenstein Review, pp. 63-79.

2. Kalpokas, I. (2019), A political theory of post-truth, Palgrave Pivot, Cham.

3. Bourbeau, P. (2016), Resilience, Security and World Politics, in The Routledge handbook of International resilience, eds Chandler, D. and Coaffee, J. New York, London, Routledge, pp. 26-37.

4. Chandler, D. and Coaffee, J. (2016), Introduction: contested paradigms of international resilience, The Routledge handbook of International resilience, eds Chandler, D. and Coaffee, J., New York, London, Routledge, pp. 3-9.

5. Crilley, R. (2018), Book review essay: International relations in the age of 'post-truth' politics, International Affairs, no. 94, pp. 417-425.

6. Mazzoleni, G. and Schulz, W. (1999), "Mediatization" of politics: A challenge for democracy? Political communication, no. 16(3), pp. 247-261.

7. Marcinkowski, F. (2014), Mediatisation of politics: Reflections on the state of the concept, Javnost The public, no. 21(2), pp. 5-22.

8. Hepp, A., Hjarvard, S. and Lundby, K. (2015), Mediatization: Theorizing the Interplay Between Media, Culture and Society, Media, Culture and Society, no. 37(2), pp. 314-324.

9. Hearn, A. (2011), Promotional culture, Encyclopedia of consumer culture, ed. by Southerton, D., CA, SAGE Publications, Thousand Oaks, pp. 1158-1160.

10. Harsin, J. (2015), Regimes of Posttruth, Postpolitics, and Attention Economies, Communication, Culture \& Critique, no. 8, pp. 327-333.

11. Lewis, P. (2018), 'Fiction is outperforming reality': How YouTube's algorithm distorts truth, The Guardian, February 2, available at: https://www.theguardian.com/technology/2018/feb/02/how-youtubesalgorithm-distorts-truth (accessed: 30.09.2019).

12. Global Commission on Internet Governance. One Internet (2016), Chatham House, London.

13. Harsin, J. (2018), Post-truth and critical communication studies, Oxford Research Encyclopedia of Communication, available at: https://oxfordre.com/communication/view/10.1093/acrefore/9780190228613.001.0001/acrefore-9780190228613-e-757 (accessed: 15.10.2019).

14. Corner, J. (2017), Fake news, post-truth and media-political change, Media, Culture \& Society, no. 39 (7), pp. 1100-1107.

15. Horsthemke, K. (2017), 'FactsMustFall'? - Education in a Post-truth, Posttruthful World, Ethics and Education, no. 12 (3), pp. 273-288.

16. Holling, C.S. (1973), Resilience and stability of ecological systems, Annual review of ecology and systematics, no. 4 (1), pp. 1-23.

17. Walker, B., Holling, C. S., Carpenter, S. and Kinzig, A. (2004), Resilience, adaptability and transformability in social-ecological systems, Ecology and society, no. 9 (2), available at: https://www.ecologyandsociety.org/vol9/iss2/art5/ (accessed: 14.10.2019).

18. Romanova, T. (2017), Resilience category in the European Union, Sovremennaia Evropa, no. 76 (4), pp. 17-28.

19. European External Action Service. Shared Vision, Common Action: A Stronger Europe. A Global Strategy for the European Union's Foreign And Security Policy (2016), Brussels, available at: http://eeas.europa.eu/ archives/docs/top_stories/pdf/eugs_review_web.pdf (accessed: 05.10.2019).

20. European Commission, Joint Communication to the European Parliament and the Council. A Strategic Approach to Resilience in the EU's external action. JOIN(2017) 21 final, 7.6, European Commission, available at: https://ec.europa.eu/europeaid/sites/devco/files/joint_communication_-a_strategic_approach_to_resilience_in_the_eus_external_action-2017.pdf (accessed: 05.10.2019).

21. Tusk, D. (2016), The battle for CETA was highly emotional, Twitter, October 30, available at: https:// twitter.com/eucopresident/status/792717582524674048 (accessed: 09.10.2019).

22. Chee, F. Y. (2019), EU's Juncker: there is still a risk of no-deal Brexit despite delay. Reuters, April 20, available at: https://uk.reuters.com/article/uk-britain-eu-juncker/eus-juncker-there-is-still-a-risk-of-nodeal-brexit-despite-delay-idUKKCN1RV1B5 (accessed: 09.10.2019). 
23. Williams, M. (2018), EU vs Fake News: The truth about Brussels' fight against disinformation, Channel 4, December 18, available at: https://www.channel4.com/news/eu-vs-fake-news-the-truth-about-brussels-fight-against-disinformation (accessed: 09.10.2019).

24. European Commission, Statement by Vice-President Ansip on the action plan to counter disinformation and progress achieved so far (press conference), December 5 (2018), European Commission, available at: https://ec.europa.eu/commission/commissioners/2014-2019/ansip/announcements/statement-vicepresident-ansip-action-plan-counter-disinformation-and-progress-achieved-so-far-press_en (accessed: 09.10.2019).

25. European External Action Service. Remarks by HR/VP Mogherini at the press conference following the Foreign Affairs Council. April 16 (2018), EEAS, available at: https://eeas.europa.eu/diplomatic-network/ european-neighbourhood-policy-enp/42996/remarks-hrvp-mogherini-press-conference-following-foreign-affairs-council_en (accessed: 09.10.2019).

26. European Commission, Joint Communication to the European Parliament, the European Council, the Council, the European Economic and Social Committee, the Committee of the Regions Action Plan against Disinformation. JOIN(2018) 36 final, 05.12 (2018), European Commission, available at: https:// ec.europa.eu/commission/sites/beta-political/files/eu-communication-disinformation-euco-05122018_ en.pdf (accessed: 16.10.2019).

27. Corry, O. (2014), From defense to resilience: Environmental security beyond neo-liberalism, International political sociology, no. 8 (3), pp. 256-274.

28. Vasu, N., Ang, B., Teo, T. A., Jayakumar, S., Raizal, M. and Ahuja, J. (2018), Fake news: National security in the post-truth era, RSIS, Singapore.

29. European Commission. A multi-dimensional approach to disinformation: Report of the independent High Level group on fake news and online disinformation (2018), Publications Office of the European Union, Luxembourg.

30. European Parliament resolution of 23 November 2016 on EU strategic communication to counteract propaganda against it by third parties (2016/2030(INI)), 23.11 (2016), European Parliament, available at: https://www.europarl.europa.eu/doceo/document/TA-8-2016-0441_EN.html (accessed: 16.10.2019).

31. Digital Single Market. POLICY. Tackling online disinformation, European Commission, Official Website, available at: https://ec.europa.eu/digital-single-market/en/fake-news-disinformation (accessed: 16.10.2019).

32. Yatid, M.M. (2019), Truth Tampering Through Social Media: Malaysia’s Approach in Fighting Disinformation \& Misinformation, IKAT: The Indonesian Journal of Southeast Asian Studies, no. 2 (2), pp. 203230.

33. Haciyakupoglu, G., Hui, J.Y., Suguna, V.S., Leong, D. and Rahman, M. F. (2018), B. A. Countering fake news: A survey of recent global initiatives, RSIS, Singapore.

34. Baade, B. (2018), Fake News and International Law, European Journal of International Law, no. 29 (4), pp. 1357-1376.

35. European Parliament resolution of 15 June 2017 on online platforms and the digital single market (2016/2276(INI)), 15.06 (2017), European Parliament, available at: https://www.europarl.europa.eu/doceo/ document/TA-8-2017-0272_EN.html?redirect (accessed: 18.10.2019).

36. European Commission, Communication from the Commission to the European Parliament, the Council, the European Economic and Social Committee and the Committee of the Regions Tackling online disinformation: a European Approach. COM(2018) 236 final, 26.4 (2018), European Commission, available at: https://eur-lex.europa.eu/legal-content/EN/TXT/?uri=CELEX\%3A52018DC0236 (accessed: 18.10.2019).

37.Digital Single Market. Code of Practice on Disinformation. September 26 (2018), European Commission, Official Website, available at: https://ec.europa.eu/digital-single-market/en/news/code-practicedisinformation (accessed: 18.10.2019).

38. European Commission, Joint communication to the European Parliament, the European Council, the Council, the European Economic and Social Committee and the Committee of the Regions Report on the implementation of the Action Plan Against Disinformation JOIN (2019) 12 final, 14.6 (2019), European Commission, available at: https://eeas.europa.eu/sites/eeas/files/joint_report_on_disinformation.pdf (accessed: 18.10.2019).

Received: November 20, 2019

Accepted: December 16, 2019

Author's information:

Yury Y. Kolotaev — Junior Researcher; yury.kolotaev@mail.ru 